\title{
A ARTE DE REINVENTAR A EDUCAÇÃO E O PAPEL DA CIBERCULTURA EM TEMPOS DE DISTANCIAMENTO SOCIAL
}

\author{
Leila Santos de Santana ${ }^{\mathrm{i}}$ \\ Lucia Helena de Andrade Santos ii \\ Luciana Velloso da Silva Seixasiii \\ Tamires Elaine Barbosa Reis ${ }^{\text {iv }}$
}

\begin{abstract}
Resumo: Este artigo aborda situações educativas ocasionadas pela pandemia mundial do novo coronavírus (SARS-CoV-2). Percorremos dispositivos legais como a Constituição da República Federativa do Brasil, a Lei de Diretrizes e Bases da Educação e a Base Nacional Comum Curricular. Argumentamos quanto ao uso das tecnologias digitais em rede como alternativa para continuidade do processo formativo no contexto da quarentena. Partimos de dois olhares de professoras e pesquisadoras e suas inserções: uma da mãe e as aulas do filho e outra da docente, junto aos seus discentes de uma instituição da rede pública. Diante das experiências e dessas duas perspectivas, reforçamos a importância de nos apropriarmos das vivências da cibercultura, visando à reinvenção educacional pós-pandemia.
\end{abstract}

Palavras-chave: Processos formativos online; Cibercultura; Distanciamento social; Coronavírus; Reinvenção educacional.

\section{THE ART OF REINVENTING EDUCATION AND THE ROLE OF CYBERCULTURE IN TIMES OF SOCIAL DISTANCING}

\begin{abstract}
This article approaches educational situations caused by the worldwide coronavirus pandemic (SARS-CoV-2). We went through legal provisions such as the Constitution of the Federative Republic of Brazil, the Law of Directives and Bases of Education and the Common National Curriculum Base. We urge about the use of digital network technologies as an alternative for continuing the formative process in the context of quarantine. We started from two perspectives of teachers and researchers and their insertions: one from a mother and her son's classes and the other from a teacher, together with her students from a public school institution. In face of the experiences and of these two perspectives shown, we reinforce the importance of appropriating the experiences of cyberculture, aiming at the post-pandemic educational reinvention.
\end{abstract}

Keywords: Online formative processes; Cyberculture; Social distancing; Coronavirus; Educational reinvention.

\section{Introduzindo a conversa}

Como será o amanhã Responda quem puder...

Samba-enredo do G. R. E. S. União da Ilha do Governador $(1978)^{\mathrm{v}}$ 
No Brasil, a crise mundial gerada pela pandemia do novo coronavírus (SARS-CoV-2) ${ }^{\mathrm{vi}}$, que teve seus impactos sentidos no começo deste ano de 2020, mas que, de acordo com informes do Ministério da Saúde, já circulam em outros países desde 2019, e dadas as formas como as instâncias governamentais têm tratado a situação, o número de contágios e óbitos encontra-se em plena ascensão.

No momento em que este texto é redigido, consultamos o site da Organização Mundial da Saúde (OMS) vii e constatamos, com pesar, que no intervalo de apenas um mês o Brasil multiplicou por cinco o seu total de mortes pelo novo coronavírus, e mesmo assim estados já cogitam medidas de flexibilizar o isolamento/distanciamento. Tais medidas são preocupantes, pois a curva de contágio do Brasil continua ascendente, diferentemente de outros países europeus e asiáticos em processo de flexibilização, cujos dados parecem indicar, no momento, estabilização no número de casos.

Contudo, a questão do distanciamento social e da quarentena em que nos encontramos tem trazido consigo uma série de mudanças em nossas formas de ser e estar no mundo, cada vez mais mediadas pelo digital em rede. Nosso intuito é identificar as mudanças acarretadas pela pandemia, principalmente no que tange às relações pessoais e aos processos formativos, portanto, nas relações 'docentesdiscentes' viii .

Para composição desta reflexão percorremos o que versa, por exemplo, a Constituição da República Federativa do Brasil, de 1988 (CRFB/88), que traz em seu bojo um preceito garantido por meio do Artigo $5^{\circ}$ :

Todos são iguais perante a lei, sem distinção de qualquer natureza, garantindose aos brasileiros e aos estrangeiros residentes no País a inviolabilidade do direito à vida, à liberdade, à igualdade, segurança e à propriedade (BRASIL, 1988, grifo nosso).

O referido dispositivo legal retrata um direito perseguido historicamente: a cidadania, trazendo com a ela o desejo de igualdade entre todos, mas que, contemporaneamente, ainda é um desejo perseguido, haja vista o fato que se contrapõe à centralização de poder e à subjugação de grupos que são colocados à margem da sociedade, na manutenção de tempos em que tal anseio não consistia em um direito.

Buscando compreender esse fenômeno dicotômico que divide a sociedade brasileira, por si só já marcadamente desigual, Araújo (2010) reflete sobre as diferentes formas pelas quais nos constituímos. O autor indica que:

A organização federativa do Estado, marcada estruturalmente pela tensão igualdade/desigualdade de coletividades políticas, tem desdobramentos no 
direito à educação, inscrito a partir do princípio da igualdade de oportunidades, a igualdade/desigualdade territorial de poder político e econômico, bem como da capacidade fiscal em incidência direta nas iguais/desiguais oportunidades de escolarização, mesmo se levarmos em conta os mecanismos de transferências intergovernamentais (ARAÚJO, 2010, p. 233).

$\mathrm{O}$ ano de 2018 contou com muitas interrogações em decorrência das designações constantes nos Artigos de 205 até 214 da CRFB/88 e advindas da Lei de Diretrizes e Bases da Educação, de 1996 (LDB/96), especialmente se lidos sob a luz da nova Base Nacional Comum Curricular $(\mathrm{BNCC})^{\mathrm{ix}}$ para a Educação Básica. Polêmicas à parte, principalmente no que se refere à consonância política, ao respeito à diversidade e à pluralidade nacional, relacionados às possibilidades de educar e ensinar em distintos 'espaçostempos', por não consistir no objetivo deste trabalho, em contrapartida é de suma importância saber como o uso da tecnologia é abordado, mesmo conscientes de que podemos fazer usos de táticas para subverter as estratégias hegemônicas, objetivando o desenvolvimento de atividades que propiciem aos praticantes 'conhecimentossignificações'. E reacendeu discussões sobre o uso das tecnologias nas diversas modalidades de 'ensinoaprendizagem', desde a Educação Infantil até o Ensino Superior.

A BNCC, que veio para atender demandas previstas na CRFB/88 e na LDB/96, conforme apresentado à sociedade, retratando uma preocupação no que diz respeito às políticas públicas no campo da Educação, é uma lei a ser cumprida. Todavia, vale indagar se nela conseguem ser ampliadas questões relativas à universalização do Ensino Fundamental e à formação de professores. Especialmente, cabe considerar o previsto no Plano Nacional de Educação (PNE), aprovado em 2014, sobre a necessidade de que a União, estados e municípios implementem direitos e objetivos de aprendizagem, de acordo com o descrito também por Caetano e Peroni (2014, p. 341), que se objetiva com eles; assim podemos compreender que se faz necessário que o aluno seja o centro desse processo, pois

aprender a ler e escrever oferece aos estudantes algo novo e surpreendente: amplia suas possibilidades de construir conhecimentos nos diferentes componentes, por sua inserção na cultura letrada, e de participar com maior autonomia e protagonismo na vida social (BRASIL, 2018).

Em conformidade com o explicitado no trecho acima, poderemos garantir a inserção na cultura letrada em ambiências formativas que propiciem a participação dos alunos, com autonomia e protagonismo, desenvolvendo diferentes conhecimentos e saberes, neste momento 
em que a Organização Mundial da Saúde (OMS) recomendou o fechamento das unidades escolares, considerando a realidade de diferentes instituições e modalidades de ensino.

A tecnologia, prevista na Base Nacional Curricular Comum (BNCC), deve ser utilizada de maneira crítica e responsável ao longo da Educação Básica, do Ensino Médio e Superior, seja estimulando o pensamento crítico, criativo e lógico, seja de forma mais proativa, tanto no processo de aprendizagem quanto no uso das tecnologias, aprofundando o letramento, a linguagem e a cultura digital como um todo, desenvolvendo, portanto, multiletramentos, usufruindo dessa maneira da tecnologia de forma consciente, crítica e responsável nos cotidianos.

As possibilidades de ações esbarram em algumas questões: as condições econômicas e sociais, bem como competências e habilidades 'docentesdiscentes', para que possam explorar e fazer uso dos artefatos tecnológicos na promoção de estratégias e, por conseguinte, experiências formativas mediadas pelo digital em rede que propiciem a comunicação síncrona e assíncrona, prestigiando a interação entre os praticantes do e no processo.

Concordamos com Santaella (2013, p. 292) quando diz que "os aparelhos móveis facilitam e instigam a constituição e coesão de grupos informais de interesses e preocupações comuns". Assim, a possibilidade de essa percepção ser considerada uma ambiência formativa pode possibilitar o desenvolvimento de processos dialógicos, interativos e colaborativos, favorecendo trocas, associações e significações (SILVA, 2003; SANTOS, 2019), além de propiciar a aprendizagem significativa, com vistas ao engajamento dos discentes. O docente, por sua vez, pode planejar situações de aprendizagem diversificadas que permitam comparar, estabelecer relações de semelhanças e diferenças, experimentar, analisar, sintetizar e sistematizar conceitos inerentes ao processo de construção e reconstrução de conhecimentos.

O pensamento trazido anteriormente, aliado à ideia de ampliação do espaço físico escolar, envolvendo os lares dos discentes, por exemplo, e não em substituição a esses, corrobora a percepção dos motivos pelos quais as tecnologias digitais podem e estão sendo adotadas como alternativa neste momento pandêmico. Entendemos que a cibercultura, por meio dos artefatos tecnológicos e especialmente em mobilidade ubíqua (SANTAELLA, 2013; SANTOS, 2019), se incorporada à prática docente, pode oferecer alternativas a uma formação significativa. De acordo com Santos (2019, p. 49),

a prática docente é capaz de contemplar a dinâmica baseada em mobilidade, ubiquidade, autoria, conectividade, colaboração e interatividade, deverá propiciar oportunidades de múltiplas experimentações e expressões, disponibilizar uma montagem de conexões em rede que permita múltiplas ocorrências e provocar situações de inquietação criadora e colaborativa. 
No sentido de somar ao que vem sendo discutido sobre o distanciamento social que vivenciamos desde março de 2020, traremos neste trabalho dois olhares de professoras e pesquisadoras que refletem sobre suas práticas e mobilizam saberes que se somam às suas formações (TARDIF, 2002). Duas vivências nesse cenário: a primeira, de uma mãe atenta às urgências sanitárias e que se alterna entre trabalhos domésticos, sua pesquisa acadêmica e orientação dos seus filhos nas tarefas escolares propostas pela instituição onde eles estão matriculados. A segunda, vivenciada por uma docente junto aos seus alunos em uma instituição da rede pública.

Percebemos que as discussões que envolvem distinções entre educação online e a educação a distância, termos que já discutíamos há muito em nosso grupo de pesquisa, e, mais recentemente, educação remota, têm sido trazidas cada vez mais à tona, o que nos instiga a nos posicionar, como pesquisadoras do campo, sobre tais questões.

Para compor nosso trabalho desenvolvido com base em método qualitativo, fizemos uso de duas diferentes metodologias, ambas com a intencionalidade de compreender como estão se forjando processos criativos para lidar com o novo que se apresentou.

Desse modo, mergulhamos com nossos sentidos vivendo os cotidianos, buscando formas de aprender com o que está posto. Refletimos e elaboramos, a partir dessas experiências, buscando formas de encontrar meios para alcançar nossos objetivos (ALVES, 2019). Posto isso, portanto, as pesquisas com os cotidianos contribuem ao nos fazer perceber as redes que se tecem em meio a situações do dia a dia por entre múltiplos fios que ajudam na tessitura de experiências vividas, gerando indícios do que está, de fato, sendo 'feitopensadofalado' pelos praticantes culturais (FERRAÇO; ALVES, 2019).

Inicialmente, trouxemos nossas considerações acerca do que foi obtido por meio do relato das experiências vivenciadas pela pesquisadora na condição de mãe de aluno que se encontra realizando atividades a distância. Os dilemas, questionamentos e as táticas por ela desenvolvidas contribuem para fomentar discussões, trocas e conhecimentos a serem adquiridos, buscando aprimorar o processo formativo do filho adolescente. Portanto, são subsídios que nos ajudam a buscar outras metodologias de pesquisa que possibilitem compreender como essas relações estão se dando.

Numa outra perspectiva, trazemos as experiências, inserções e mediações de uma 'professorapesquisadora' com quatorze de seus trinta e dois alunos da etapa inicial da Educação de Jovens e Adultos de uma escola da rede pública de Duque de Caxias, no Estado do Rio de Janeiro. Nesse contexto, optamos pela pesquisa-formação multirreferencial na cibercultura (SANTOS, 2019), por entendermos ser essa uma metodologia que oportuniza 
desenvolver a pesquisa adotando um olhar múltiplo, também atento às práticas educativas, a partir de distintas referências que se interligam, quase como um hiperlink de conhecimentos e saberes que constituem e formam os praticantes da pesquisa.

Entendemos que a pesquisa-formação multirreferencial na cibercultura tem suas bases nos princípios de compromisso e implicação do pesquisador com suas práticas, pressupondo, consequentemente, a intervenção participativa na realidade social investigada, nos cotidianos, reconhecendo que nele formamos e somos formados, numa relação interativa permeada de 'conhecimentosignificações'.

Em consonância com essa metodologia, trazemos o trabalho no qual a docente faz uso do aplicativo WhatsApp (PORTO; OLIVEIRA; ALVES, 2017), aqui entendido como dispositivo tecnológico pedagógico. Tal dispositivo tem se apresentado como de grande relevância para o que podemos entender como processo de reinvenção educacional durante e pós-pandemia.

Nesse movimento de busca para adequar-nos às demandas colocadas pelo isolamento social, vivenciamos experiências em locus distintos, mas que interagem e se complementam na ação de relatar o que foi vivido e 'aprendidoensinado'.

\section{Alguns pressupostos}

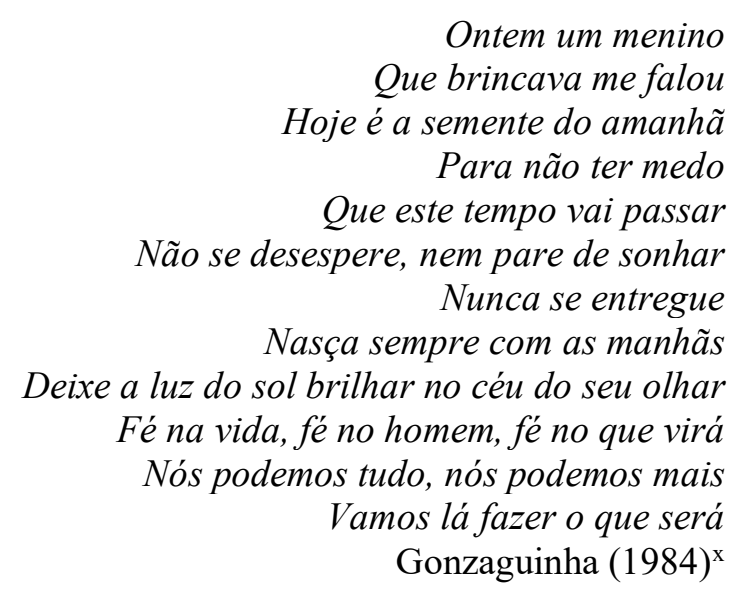

O contexto de pandemia provocado pelo invisível coronavírus fez com que muitas escolas permitissem o uso de dispositivos digitais em rede para desenvolvimento das atividades pedagógicas, na busca por soluções educacionais para dar continuidade ao currículo escolar, na medida em que as prevenções oriundas dos relatórios da Organização Mundial da Saúde (OMS) definiram critérios de distanciamento social. 
A partir daí, muito se tem discutido sobre a modalidade de educação a distância neste momento. Diante disso, discutiremos com base na Lei de Diretrizes e Bases da Educação Nacional $(\mathrm{LDB} / 1996)^{\mathrm{xi}}$, especificamente no Artigo 80, que aborda a possibilidade de a educação a distância ser trabalhada em todos os níveis e modalidades de ensino, ou seja, na Educação Básica e na Educação Superior. No entanto, é importante frisar que, antes mesmo da explosão da internet e dos usos das mídias digitais, a educação a distância era realizada via cursos disponibilizados por meios massivos de comunicação; dito de outro modo, ela se fazia presente na educação antes mesmo do contexto da cultura digital em que estamos cada vez mais imersos.

Em virtude dos fatos mencionados, traremos para esta discussão as reflexões de Santaella (2003) quando, ao discutir as mídias digitais em rede, evidencia a importância da linguagem nesse processo e ressalta que

processos comunicativos e formas de cultura que neles se realizam devem pressupor tanto as diferentes linguagens e sistemas sígnicos que se configuram dentro de veículos em consonância com o potencial e limites de cada veículo quanto deve pressupor também as misturas entre linguagens que se realizam nos veículos híbridos de que a televisão, e muitos mais, a hipermídia são exemplares (SANTAELLA, 2003, p. 116).

Em vista disso, concordamos com a autora quando ela afirma que as mídias só têm efetivamente sentido quando nelas estão as linguagens, ou seja, as diversas formas de expressão que a humanidade construiu e vem construindo com as mudanças culturais e, de certa forma, a partir das mudanças nas mídias.

Desse modo, Santaella (2003) apresenta-nos as seis eras culturais das mídias: cultura oral, escrita, impressa, massas, mídias e cibercultura. Para tanto, neste espaço discutiremos mais proximamente a cibercultura, considerada por Santos e Araújo (2012) como a cultura contemporânea mediada por tecnologias digitais em rede. Tendo em vista que é importante deixar claro que as culturas e as linguagens nelas configuradas vão se entrelaçando e se complementado, dessa maneira não há relação de exclusão entre elas.

$\mathrm{O}$ contexto pandêmico no qual estamos vivendo trouxe à tona discussões muito importantes sobre a cultura na qual estamos imersos e a educação, ou seja, as formas de produzir conhecimentos na linguagem digital. Dessa maneira, a cibercultura revoluciona as formas de comunicação com base nos três princípios básicos apontados por Lemos (2003): 1) a liberação do polo de emissão; 2) conectividade generalizada e 3) reconfiguração social. Dessa forma, posicionamo-nos favoravelmente à Educação online como um fenômeno da cibercultura, atentos a não vê-la na posição de extensão ou atualização da modalidade de educação a 
distância, mas como possibilidade de formar cidadãos críticos e reflexivos capazes de compreender a sua existência a partir da relação com o mundo e, assim, colocar em prática a práxis educacional tanto defendida por Paulo Freire em suas obras.

Concordamos com Santos, (2018, p. 24) quando afirma que "a Educação online é uma modalidade de educação que pode ser vivenciada ou exercitada para potencializar situações de aprendizagem mediadas tanto por encontros presenciais quanto a distância”, pois a relação cidade e cibercultura em discussões teóricas não foram vistas separadamente; o mundo físico e digital caminham lado a lado.

Em conversas recentes sobre Educação online em tempos de pandemia ${ }^{x i i}$, a professora Edméa Santos trouxe alguns pressupostos para sua compreensão. Durante a conversa, Santos (2020), em consonância com as ideias de Silva (2003), articula a noção de Educação online com a interatividade "na disposição para mais e mais interação, para uma hiperinteração, para a bidirecionalidade - fusão emissão recepção -, para a participação e intervenção" (SILVA, 2003, p. 29). Com isso, entendemos que duas palavras chave para a interatividade são a comunicação e a autoria.

Ao discutir sobre a Educação a Distância e a Educação online, esta última um fenômeno cibercultural, Pimentel e Carvalho (2020) apresentam oito princípios: 1) Conhecimento como obra aberta; 2) Curadoria de conteúdos mais sínteses e roteiros de estudo; 3) Ambiências computacionais diversas; 4) Aprendizagem em rede, colaborativa; 5) Conversação entre todos, em interatividade; 6) Atividades autorais inspiradas nas práticas da cibercultura; 7) Mediação docente online para colaboração; 8) Avaliação formativa e colaborativa, baseada em competências.

Assim, dialogando com o exposto acima, é importante pensar e propor práticas pedagógicas inspiradas nos princípios da Educação online em atos de currículos ${ }^{\text {xiii }}$ ou seja, pensamos um currículo vivo que combine ambiências dialógicas que possibilitem que todos os praticantes envolvidos vivenciem o 'aprenderensinar' de forma que não seja um movimento de transportar os conteúdos curriculares produzidos no presencial para o digital, mas sim proporcionar intencionalidades pedagógicas que possam provocar situações de aprendizagem mediadas pelo digital em rede.

\section{Sobre nossas múltiplas identidades e inserções}

Eu prefiro ser essa metamorfose ambulante

Do que ter aquela velha opinião formada sobre tudo Raul Seixas $(1973)^{\mathrm{xiv}}$ 
Com o isolamento social proposto para evitar a contaminação pelo novo coronavírus, muitos profissionais e pesquisadores precisaram adaptar seu trabalho e estudo, com realização de trabalho remoto, acrescido pela responsabilidade de acompanhar a realização das atividades propostas pelas escolas, sobretudo particulares, para crianças e adolescentes; numa nova realidade com as aulas presenciais suspensas, os estudantes em casa, o dia todo, fazendo do celular e do videogame suas companhias prediletas. Sem hora para dormir, sem compromisso para acordar.

Quando a escola preparou aulas na modalidade a distância, mesmo que a princípio acreditava-se ser temporário, a expectativa dos pais, sua preocupação era com a ociosidade dos filhos e garantir o ano letivo; dessa forma, foi encarada como uma ação benéfica para a manutenção do aprendizado.

Neste tópico, o texto trará as experiências de uma das pesquisadoras com filhos no sétimo ano do Ensino Fundamental e no primeiro ano do Ensino Médio de escolas particulares da cidade do Rio de Janeiro. Embora com variações na organização de muitas famílias, os enfrentamentos e descobertas são comuns nesse movimento 'ensinoaprendizagem' produzido online sem precedentes e sem testes preliminares.

No início do ano letivo de 2020, uma das escolas já havia proposto o aplicativo Google Classroom $^{\mathrm{xv}}$ como dispositivo para que os 'docentesdiscentes' pudessem interagir. O objetivo, conforme comunicado enviado aos pais, seria utilizar o dispositivo como um ambiente virtual de aprendizagem (AVA), uma nova ambiência para produção textual. As aulas presenciais não foram modificadas e no primeiro momento o aplicativo se restringia ao compartilhamento de vídeos e textos, de forma unilateral, e para tirar dúvidas sobre tarefas escolares.

Entretanto, uma nova realidade foi imposta pela pandemia, e o Decreto $n^{\circ} 46.980$, de 19 de março (RIO DE JANEIRO, 2020) ${ }^{\mathrm{xvi}}$, suspendeu as atividades escolares para conter a curva de crescimento da pandemia do novo coronavírus; subsequentemente ocorrem novas prorrogações de prazo de retorno às aulas. Dessa maneira, a escola iniciou os preparativos para disponibilizar atividades a distância a partir de 30 de março.

O aplicativo Google Classroom foi proposto para o $7^{\circ}$ ano do Ensino Fundamental para atividades síncronas (online) e assíncronas (offline). A familiaridade com a plataforma não foi um entrave, pois os alunos já a utilizavam como complemento a atividades escolares, mas no começo nem todos os professores utilizaram a plataforma; alguns deles compartilhavam vídeos do YouTube com assuntos da matéria para manter os alunos atualizados.

As aulas a distância aconteciam via aplicativo de videoconferência Google Meet ${ }^{\text {xvii }}$. No primeiro dia de aula, a mãe encontrou o adolescente demonstrando seu desconhecimento sobre 
práticas desse tipo, pois estava vestindo o uniforme da escola para participar das aulas que foram organizadas no mesmo horário que aconteciam presencialmente, com horário fixo para cada professor e intervalo entre eles, numa tentativa de reproduzir rotina da aula presencial, mesmo com os alunos geograficamente dispersos. Nessa nova configuração, os alunos estão de pijama, o gato atrapalha e o jogo preferido está na tela, minimizado. Nessa realidade, na qual os adolescentes estão em seus quartos com celular e/ou computador ligado, caso a aula fique maçante, basta abrir outra tela com jogos ou usar o fone de ouvido para ouvir sua música favorita. Alguns adolescentes não querem que os pais assistam às aulas, transformando em um grande desafio essa relação alunofilho ${ }^{\text {xviii }}$ com responsáveis desejosos por aprender a ser fiscais e filhos querendo espaço.

Ajustar a rotina familiar a essa nova realidade exige concessões e desafios. Com a obrigatoriedade de pais trabalharem em home office e filhos com aulas todos os dias, a organização para o uso dos computadores da casa se tornou necessária, pois assistir a aulas pelo celular durante quase cinco horas é inviável, devido ao tamanho da tela e à dificuldade de acesso aos arquivos durante uma chamada, contexto que ressaltou a importância do dispositivo tecnológico para desenvolvimento das tarefas escolares e em home office.

Os prazos acadêmicos foram modificados para tornar mais justa a apresentação das atividades para todos os afetados pela pandemia, mas a rotina em casa com todos habitando os mesmos espaços e compartilhando/usando ao mesmo tempo os dispositivos tecnológicos apresenta-se como uma situação que, agregada a outras, causa preocupações, especialmente em meio aos caos da desinformação que se tornou o gerenciamento da crise de saúde no país. Neste momento de situações que fogem ao controle, apropriamo-nos de Certeau (1998), entendendo que é preciso lançar mão de táticas para desafiar a ordem estabelecida, adaptando os cotidianos aos praticantes.

Além do mais, os pais precisam 'aprenderensinar' Língua Portuguesa, Matemática, Física e Química. “A constante de Avogadro ser invariável pode ser um pleonasmo ou uma

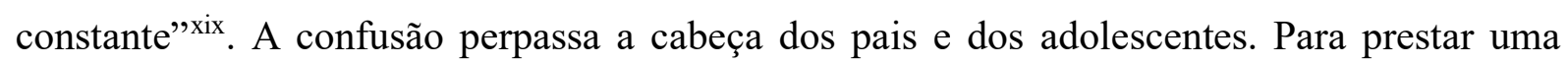
monitoria aos estudos são necessários conhecimentos que por vezes os familiares não se sentem aptos a satisfazer.

Da mesma forma, há situações ocasionadas por alunos com diferentes níveis de atenção, especialmente quando um deles possui transtorno de déficit de atenção e hiperatividade $(\mathrm{TDAH})^{\mathrm{xx}}$, apresentando dificuldade em acompanhar as aulas; desse modo precisando de ajuda para se desvencilhar de várias distrações enquanto o professor do outro lado se esforça para manter a turma atenta. 
O uso da tecnologia como artefato curricular para desenvolvimento da prática pedagógica ainda é novidade para alguns professores, por isso eles transportam para o ensino a distância (remoto) a exposição de assuntos do ensino presencial, como indicam Pimentel e Araújo (2020). Os autores recomendam o uso dos diversos meios de conversação todos-todos para realizar dinâmicas de conversação em grupo, além de que, como defendido por Santos e Araújo (2012, p. 116), "a educação mediada pelas tecnologias digitais são sempre processos a serem desenvolvidos e não simplesmente executados", exigindo uma construção cotidiana.

A proposta de uma das escolas para realização das avaliações com provas online, ou seja, com o aluno recebendo a prova por meio do aplicativo e devolvê-la através dele, sem vigilância, sem tempo para finalização da tarefa, como realizado por uma das unidades, causa estranhamento, principalmente ante a descoberta de que várias questões da prova já estavam no Branly ${ }^{x x i}$ (site de resolução de questões), uma vez que a mesma prova é utilizada por diferentes filiais da rede de escolas do Rio de Janeiro.

Vale indagar sobre o tipo de avaliação utilizado. Quais os saberes avaliados por meio da prova compartilhada? Os resultados obtidos na avaliação serão apreciados no retorno das aulas presenciais, num contexto de uma nova normalidade? E nesse retorno os alunos estarão no mesmo nível de aprendizagem?

Para auxiliar na reflexão sobre essas indagações, Santos e Araújo (2012, p. 104) ressaltam que nas avaliações na Educação online é preciso criar dispositivos com interfaces "claramente organizadas no contexto do desenho didático do curso" (SANTOS; ARAÚJO, 2012, p. 105).

Entretanto, a Educação a Distância é indicada para adultos e requer execução de atividades pedagógicas planejadas e treinamento do aluno em como estudar; "deve-se ter cautela em utilizar apenas atividades escolares remotas em períodos de crise como a que vivemos atualmente" (JUNQUEIRA, 2020, s/p).

Nas avaliações paralelas a essas provas, a utilização do digital em rede mostra um espaço mais criativo, prazeroso e significativo, com produção de vídeos, utilização de videoconferência entre alunos, letramentos que poderão auxiliá-los no processo de produção de conhecimento com o uso de múltiplas linguagens (som, vídeo, texto e imagem).

Um 'novo' normal se estabelecerá a partir da volta às aulas, e os dispositivos móveis, anteriormente encarados como vilões em algumas salas de aula, podem adquirir novo sentido, novo status, pois durante a quarentena foram amplamente utilizados como suporte às aulas.

No futuro, as escolas poderão utilizá-los em suas práticas pedagógicas ou talvez desprezar a experiência adquirida nesta fase com o retorno das aulas presenciais. Pais, alunos e 
professores retomaram as suas rotinas e muitas práticas de ensino remoto podem reverberar na sala de aula presencial, possibilitando maior participação das tecnologias digitais em rede, como já observava Certeau (1998, p. 105): “o estudo de algumas táticas cotidianas presentes não deve, no entanto, esquecer o horizonte de onde vêm e, no outro extremo, nem o horizonte para onde poderiam ir".

Passamos então, a seguir, a analisar possíveis legados deste momento de pandemia sobre as relações educacionais que se darão ou que já podem estar se dando, basta que atentemos a elas.

\section{'Docentesdiscentes' e as potencialidades formativas do digital em rede}

Há uma luz que vem pra me dizer: tudo vai dar certo E os inimigos que eu não posso ver não terão mais força

$E$ as coisas boas que eu imaginar se tornarão vivas

E os pensamentos positivos serão minha fortaleza

Natiruts (2020) $)^{\mathrm{xxi}}$

As tecnologias digitais avançaram perceptivelmente nas atividades cotidianas, nas relações existentes entre a cidade e o ciberespaço. Considerando, especialmente, as demandas decorrentes da crise pandêmica global em que vivemos - já abordada em tópicos anteriores por conseguinte, do distanciamento geográfico necessário entre as pessoas, foram se dando as mudanças na relação 'docentesdiscentes', ensejando a necessidade de uma abordagem metodológica diferente da comumente empregada no campo educacional.

O uso das tecnologias digitais, principalmente como colocado por Santaella (2013), em contexto de mobilidade ubíqua, pode potencializar práticas formativas, sobretudo se considerarmos que, ainda na atualidade, a democratização do uso dessas tecnologias em rede não é garantida, pela falta de uma internet de qualidade e acessível a todos, apesar de consistir em um direito humano, conforme previsão no Marco Civil da Internet (Lei $\left.n^{\circ} 12.965 / 14\right)^{x x i i i}$, essencial ao exercício da cidadania, e de desenvolvimento de multiletramentos digitais, dentre eles os letramentos políticos e os críticos.

As instituições educacionais possuem um ecossistema pedagógico (PRETTO, 2013) que conta com a participação e a criação de toda a comunidade, sendo capaz de diversas produções culturais e de elaboração de conhecimentos. A esse ecossistema pedagógico podemos acrescentar as tecnologias digitais em rede, que, num cenário de normalidade e em potência, são capazes de enriquecê-lo e se apresentar como alternativa viável de interação, 
considerando as diretrizes sanitárias de distanciamento fixadas, contrapondo-se aos modelos tradicionais de escolarização.

Desta maneira, a inclusão dessas tecnologias respalda a possibilidade de usar as interfaces presentes nos dispositivos tecnológicos digitais e em rede (SANTOS, 2019) para compor ambiências formativas diversas e soluções educacionais, principalmente frente à urgência de planejamento para enfrentamento deste momento pandêmico.

Ressaltamos que, apesar de reconhecer o avanço nos usos das tecnologias digitais nos processos de produção de conhecimentos, a percepção das desigualdades de acesso em diferentes contextos, como na rede pública e na rede particular, tornou-se ainda mais evidente, face à arquitetura que ambas apresentam. São desigualdades que se traduzem em capacidade econômica e social, bem como na habilidade e nos usos dados a essas tecnologias, que consistem em fatores determinantes para a rapidez e adequação a uma nova configuração educacional.

Dessa maneira, para essa configuração social, como alerta Pretto (2013, p. 30), é premente "pensar a educação fortemente articulada com a cultura, com as telecomunicações, ciência e tecnologia", na qual todos, sem distinção, tenham acesso satisfatório, sem distinções, transformando, principalmente, a realidade escolar da rede pública, dado que:

quem não está conectado estará excluído de maneira cada vez mais intensa e variada. A brecha acirra os contrastes entre regiões, países e grupos sociais. (...) Inversamente, quanto mais se reduz a brecha, mais avança na integração social, democracia comunicacional e igualdade de oportunidades produtivas, tanto dentro dos países quanto entre eles (GARCIA CANCLINI, 2009, p. 236237).

Assim, entendemos que tanto a democratização dos dispositivos quanto a das redes digitais, por influenciarem diretamente no modo de agir, pensar e articular os processos educacionais, têm que se constituir em uma de nossas principais pautas de luta no contexto atual.

A possibilidade de enviar ou receber informações é inerente ao leitor ubíquo, como trazido por Santaella (2013), ou em mobilidade ubíqua, como disposto por Santos (2019), característica que oportuniza a conexão e o compartilhamento de mensagens e informações em qualquer lugar ou momento, aumentando a possibilidade de interação e de (re)organização diante do que temos vivenciado neste cenário pandêmico, permeado de imprevisibilidades, como a suspensão das aulas presenciais.

Dessa maneira, trazemos o momento vivenciado por uma das autoras, docente em uma turma da Educação de Jovens e Adultos na rede pública do município de Duque de Caxias, 
Estado do Rio de Janeiro, lócus da ação pedagógica a partir da qual ouvir as narrativas dos praticantes culturais (FERRAÇO; SOARES; ALVES, 2018) dos alunos e observar suas reações foi a primeira etapa para elaboração do planejamento para que as questões suscitadas fossem experiências exitosas, especialmente sem fazer usos de modelos massivos.

Exemplificando uma possibilidade, uma alternativa para atender as novas urgências e demandas decorrentes da crise sanitária, trazemos as inter-relações existentes entre os alunos da Educação de Jovens e Adultos e sua docente, destacando as narrativas ocorridas no processo em que as tecnologias digitais em ambiências formativas híbridas foram usadas no contexto dessa modalidade de formação (SANTANA; AMARAL, 2020).

O WhatsApp é uma interface usada para potencializar a formação, uma vez que propicia comunicabilidade entre os praticantes e a troca de conteúdos e atividades (SANTOS, 2019), compondo uma ambiência hibrida, cuja escolha se justifica por ser uma alternativa, um meio articulado para desenvolvimento do processo formativo que proporciona a ampliação do 'espacotempo' de aprendizagem, podendo ela acontecer 'dentrofora' do espaço formal da escola.

Figura 1: Usos dos smartphones no processo de 'ensinoaprendizagem'

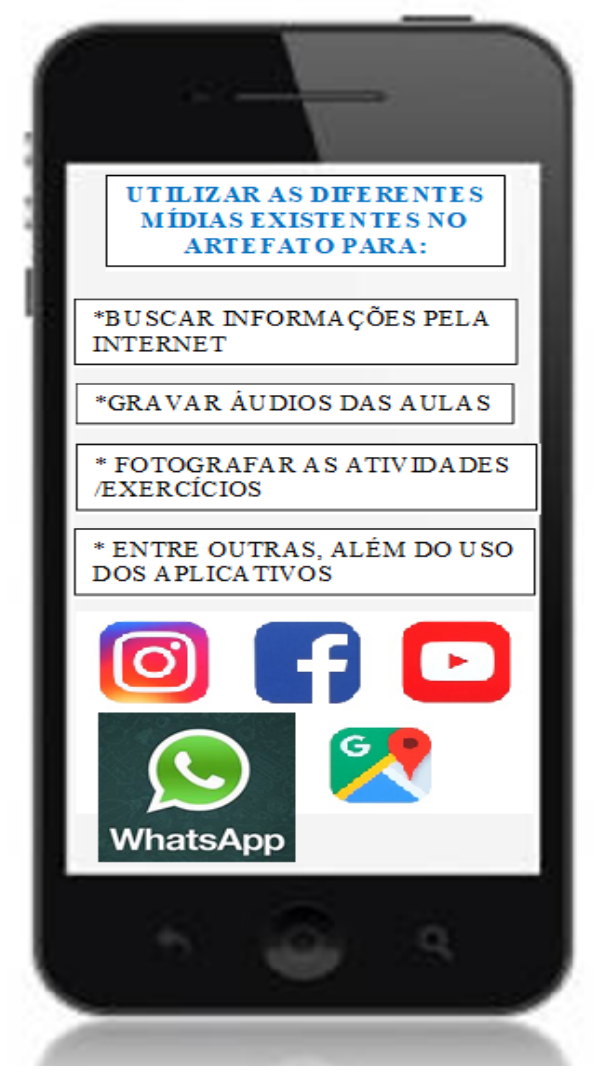

Fonte: Arquivo das autoras (2019). 
Assim, refletir acerca da realidade social dos alunos e seus cotidianos, nos quais invariavelmente o smartphone/Iphone, que permite comunicabilidade ubíqua e acesso a diferentes aplicativos, está presente, é relevante, sendo esse um artefato tecnológico com convergência de mídias digitais, diferentes interfaces e linguagens (Figura 1), como explicitado por Santos (2019).

Dentre essas possíveis interfaces incluímos as redes sociais e destacamos o WhatsApp Messenger, que permite enviar e receber textos multimodais, gravar áudios e vídeos com dados mais leves (PORTO; OLIVEIRA; ALVES, 2017) e, no atendimento às demandas sociais, atualmente faz ligações de vídeo com até oito pessoas $(\mathrm{G1}, 2020)$ e, a partir de um link, abre uma sala de conferência para até cinquenta pessoas.

Considerando a importância dessas abordagens, a urgência em desenvolver atividades em distanciamento social e, a partir delas, obter bons resultados, trazemos algumas que consideraram os cotidianos desses praticantes e os potenciais existentes no ciberespaço. Essas abordagens foram desenvolvidas pelos atores desse processo, docente e discentes, de forma que vivenciassem, afetassem e fossem afetados por uma interface já utilizada nos cotidianos, porém reconfigurada para artefato tecnológico curricular passível de enriquecer a formação dos praticantes, numa pesquisa-formação multirreferencial ${ }^{\text {xxiv }}$ no contexto cibercultural.

Compreendemos, a partir de Macedo (2014), que o processo de formação precisa ser significativo e, como destacado por Alves (2019), considerar os cotidianos dos praticantes nele envolvidos, sendo esses, portanto, aspectos fundamentais para elaboração das estratégias utilizadas para contactar os alunos, planejar e estruturar as atividades inicialmente propostas e que foram, gradualmente, adaptadas.

Todavia, o desenvolvimento dessas ações mostrou-se insuficiente para diminuir a ansiedade acerca das escolhas feitas, a partir da proposta da Secretaria de Educação e das conversas entre os profissionais (docentes e equipe diretiva) da escola em que uma das autoras desenvolve suas atividades.

Dentre essas ações destacamos:

- Criar o grupo no WhatsApp, cuja existência foi divulgada por meio de uma rede formada com alunos da turma e através das redes sociais, usando o Facebook da escola;

- Fazer um levantamento para saber quantos e quais alunos tinham acesso à rede por meio de cabo/wi-fi ou com pacotes de dados, pois este último restringe alguns acessos; 
- Realizar chamada de vídeo para que, numa comunicabilidade síncrona, conversássemos sobre o momento vivenciado, as facilidades e dificuldades no acesso e uso das tecnologias digitais em rede pelos membros da turma;

- Explicar a importância da interação para que pudéssemos falar sobre nossas dúvidas, aproveitando a comunicação para estimular a colaboração, principalmente devido à dificuldade no acesso que alguns estavam relatando.

Descobrir que alguns alunos foram atingidos pelos efeitos da pandemia, seja porque perderam entes queridos, seja porque se encontravam assoberbados com o cuidado dos que se encontravam doentes, trouxe mais impacto à percepção de que lutar contra as fragilidades e preocupações causadas pelo coronavírus não poderia ser isolado.

Certeau (1998) ajuda na reflexão de que no social e nas práticas cotidianas nos apropriamos de nosso campo de pesquisa por meio de gestos, narrativas e de outras tantas formas de expressão. Elas indicam a melhor forma de caminhar e agir. Desse modo, a empatia aproxima, não isola. Ela fortalece, agrega, não permite a solidão. Assim, não era momento de aparentar força diante dos alunos e alunas, mas de 'aprenderensinar' com nossas vivências cotidianas.

Assim, em uma configuração de distanciamento social, o desejo de estudar, conhecer, não se isolar e manter contato era importante, pois não haveria um responsável por trás do aluno, obrigando-o a interagir e fazer atividades. Saber como todos estavam consistia numa condição fundamental para as táticas pensadas, tendo em vista que elas são usadas e se adéquam à oportunidade, à situação (CERTEAU, 1998) para surtir o efeito planejado.

Dessa maneira, as ligações de vídeo objetivavam atender discentes com diferentes formas de acessos às redes digitais. Marcavam o cuidado, a atenção com o outro, pois as ligações permitiam conversas e interações mais aproximadas. Fica clara a importância da mediação docente e da constante interlocução para realização das atividades, pois possibilitava orientar e acompanhar o acesso; oportunizar aos praticantes a exposição das suas dificuldades, experiências, interesses e conhecimentos, objetivando uma construção colaborativa do processo de formação, com a percepção de todos os atores envolvidos no processo.

As interações proporcionaram a gradativa adequação do processo em decorrência do desenvolvimento do letramento digital, considerando o direito e o respeito à inclusão digital e, por conseguinte, à inclusão social (ROJO, 2013), modalidade de letramento que abre espaços de acesso ao conhecimento, à informação. Posto isso, é importante ressaltar e acrescentar que a geração de aprendizes desse letramento é composta não apenas por crianças e adolescentes, 
como afirmado por Xavier (2005), pois no ato de letrar digitalmente incluem-se adultos que em diferentes espaços vivenciam os avanços tecnológicos.

Com base nessa interação, fomos adequando o formato e a forma como as atividades eram compartilhadas no grupo do WhatsApp, acompanhando as descobertas feitas pelos alunos, que iam desenvolvendo o letramento digital. Elas se deram a partir desta ordem: 1) imagem; 2) documento do Word; 3) documento em PDF, com a existência de hiperlink.

Os ambientes online permitem a integração de distintos 'espaçostempos', o uso de uma multiplicidade de linguagens, de textos contemporâneos e outras tantas formas e modos de comunicação, como explicitado por Rojo (2012), numa interação de semioses; uma metodologia pedagógica focada nos processos formativos. Dessa maneira, ela oportuniza o desenvolvimento dos letramentos político e crítico, nos quais o uso dos dispositivos tecnológicos como artefatos curriculares não consiste numa simples forma de compartilhar materiais e atividades.

Posto isso, nasce a discussão acerca de notícias contemporâneas, dentre elas a pandemia, proposta pelos diferentes atores do processo (docentes e discentes), na qual abordamos os sintomas, cuidados, formas de contágio e efeito sobre as relações que não se constituíram em total isolamento, considerando a realidade de considerável parte da população, no que tange às condições de moradia, mas exigia no mínimo distanciamento.

Como produto da discussão descrita, propusemos a produção de vídeos com uma perspectiva diferente para construção e expressão de momento e perpassou opinião, que partiu da percepção que tínhamos das ações adequadas ao reconhecimento do que foi apreendido a partir da leitura e da prática, ou seja, ações concretas, pois, como defendido por Cope e Kalantiz (2006), perceber que o que está sendo aprendido é útil mantém a motivação daquele que aprende.

Dessa maneira, a atividade constitui-se em um evento no qual, podemos ressaltar, foi possível o desenvolvimento de letramentos digitais, políticos e críticos; portanto, multiletramentos, como citamos anteriormente; isso remete à ideia de que educar, na atualidade, requer adotar uma pedagogia plural, numa perspectiva crítica.

Concordamos que é essencial fazer uso de uma escuta atenta, com uma perspectiva pedagógica de entretecimento entre currículo, formação (MACEDO, 2014) e oportunidade, considerando que o docente contemporâneo deve buscar uma prática integradora de saberes. Além disso, ao observar o perfil do WhatsApp de um dos alunos, sugere a partir dele iniciar discussões e atividades sobre a temática (Figura 2), encaminhando letramento como uma prática 
concreta e social, partindo de eventos de letramento, em conformidade com os estudos de Street (2003).

Figura 2: Print do perfil de um dos alunos da turma

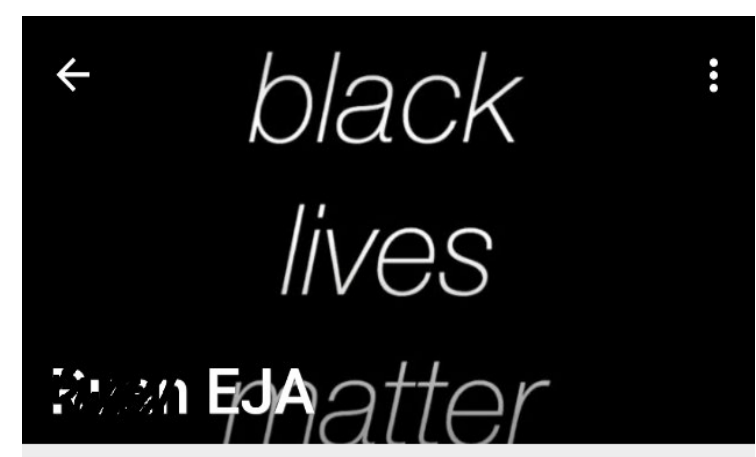

Mídia, links e docs

$47>$

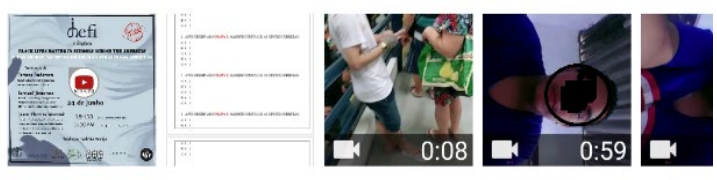

Fonte: Arquivo das autoras (2019).

O processo de reconfigurar as atividades tornando-as mais atrativas e significativas encaminha a busca por alternativas e descobertas. Durante um 'jogo', nem sempre as regras são alteradas, mas os jogadores podem melhorar seus equipamentos. A troca por um dispositivo tecnológico mais recente permitiu à aluna o acesso a outras interfaces, remetendo à ideia de que "a cibercultura é a cultura contemporânea estruturada pelo uso das tecnologias digitais nas esferas do ciberespaço e das cidades" (SANTOS, 2019, p.23). Esse novo aparelho oportunizou uma praticante conhecer virtualmente a cidade que ainda não conhecia, utilizando-o, em um passeio virtual ao Museu do Amanhã ${ }^{x x v}$. conhecendo novos locais da cidade, mesmo sem sair de casa.

São ambiências que possibilitam a promoção de distintos eventos de letramento a partir de novos usos, de estratégias que possibilitem experiências formativas, nesse processo educativo na pandemia; sem dúvida deixaram legados para seguirmos reconstruindo nosso mundo.

\section{Porque seguimos acreditando na resistência}

Mas é claro que o sol

Vai voltar amanhã

Mais uma vez, eu sei

Escuridão já vi pior

De endoidecer gente sã

Revista Interinstitucional Artes de Educar. Rio de Janeiro, V. 6 - N. Especial - pág. 301 - 324 - (jun. - out. 2020): 
Não podemos, frente à situação em que estamos tentando ofertar atividades plurais aos alunos, afirmar que não há problema com relação à inclusão cibercultural 'docentediscente'. Diariamente buscamos formas e formações para lidar com as dificuldades que emergem em nossos cotidianos.

É primordial afirmar em nossa prática cotidiana, e em diferentes ambiências, que a falta da democratização no acesso às tecnologias e à internet não pode ser naturalizada, assim como a inexistência de ações para sua oferta a todos, uma política educacional que prime pela educação para e com o digital em rede.

Questionamos a ideia de encarar com normalidade o fato de alguns alunos não acessarem as atividades que são oferecidas pelas instituições educacionais, não tendo como manter comunicação síncrona em decorrência da dificuldade do acesso. Dificuldades que enfatizam os processos de exclusão desrespeitam um direito humano de acesso à internet e a redes digitais de comunicação e interação.

Posto isso, aumentar ou no mínimo manter o quantitativo de alunos participando das atividades é um desafio; entretanto, fazer algo esbarra nas repetidamente citadas 'dificuldades tecnológicas': os dados acabam! Os celulares quebram! Porém já temos, principalmente na Educação Básica, ciência dos entraves. Assim o questionamento: 'Fácil?' pode rapidamente ser respondido com um 'não'. A letra da música cantada pela Elis Regina, "Vivendo e aprendendo a jogar; nem sempre ganhando, nem sempre perdendo; mas aprendendo a jogar"xxvii retrata a vida do docente. E seguimos na luta.

Os conflitos que vivenciamos decorrem de situações reais, de políticas públicas inadequadas às necessidades educacionais; dependem, segundo Morin (2014), do combate e constante busca de melhores condições de trabalho para os docentes, dentre elas a atualização de sua prática. Nesse sentido, o artigo apresenta experiências vividas pelas pesquisadoras durante este momento de epidemia pelo coronavírus, por considerarmos que serão emblemáticas de um contexto social mais amplo e que necessita de registros e trocas de experiências.

Reforçamos aqui a importância de nos apropriar das experiências de educação via dispositivos digitais em rede, cada vez mais ressaltando a necessidade de uma formação docente que esteja atenta às demandas do digital em rede. Contudo, reforçamos o quanto ainda é necessário que se façam investimentos e outros pontos a se discutir para o novo normal que virá no pós-pandemia. 
Podemos discorrer sobre serem necessárias abordagens e discussões mais aprofundadas sobre as vantagens, desvantagens e potencialidades de cada modalidade de ensino (presencial, a distância e o híbrido), bem como o que será feito a partir das construções desenvolvidas nesse período de distanciamento, que, cremos, não devem se constituir em apenas mais um capítulo da História da Educação.

Outro aspecto a ser apontado versa sobre a oferta de uma banda larga de qualidade para as instituições educacionais; de programas que viabilizem a criação, distribuição e avaliação do trabalho pedagógico, que não impliquem a 'doação' da propriedade intelectual docente ante a inexistência ou fragilidade na oferta desses recursos desvinculada de grandes empresas privadas de gerenciamento dos mesmos e ainda de ações afirmativas que propiciem a democratização no acesso aos dispositivos tecnológicos e, por conseguinte, não seja tão evidente a discrepância entre as condições oferecidas pelo ensino privado e as ofertadas pelo ensino público consequentemente, as desigualdades sociais, dentre outras questões há muito desconsideradas.

Seguimos acreditando e defendendo que, no momento de distanciamento social e impossibilidade de manter nossos contatos de modo presencial, a exploração dos dispositivos mediados pelo digital em rede seja vista como alternativa e forma de resistência. E, retomando nosso título, isso vai nos demandar uma reinvenção que não prescinde da arte e de nossa capacidade de nos adaptar e aprender com o novo, dia após dia.

Os sonhos são projetos pelos quais se luta. Sua realização não se verifica facilmente, sem obstáculos. Implica, pelo contrário, avanços, recuos, marchas às vezes demoradas. Implica luta. Paulo Freire (2000)

\section{Referências}

ALVES, N. Práticas pedagógicas em imagens e narrativas: memórias de processos didáticos e curriculares para pensar as escolas hoje. São Paulo: Cortez, 2019.

ANDRADE, N.; CALDAS, A. N.; ALVES. N. Os movimentos necessários às pesquisas com os cotidianos após muitas 'conversas' acerca deles. In: OLIVEIRA, I. B.; PEIXOTO, L. F.; SUSSEKIND, M. L. (Orgs). Estudos do cotidiano, currículo e formação docente. Curitiba: CRV, 2019. p. 19-45.

ARAÚJO, G. C. de. Direito à educação básica. Revista Retratos da Escola, Brasília, v. 4, n. 7 , p. 231-243, jul./dez. 2010. Disponível em: $<$ http//www.esforce.org.br $>$. Acesso em: jan. 2019. 
BRASIL. Constituição da República Federativa do Brasil. Brasília, 5 de outubro de 1988. [Atualizada até a Emenda Constitucional $\mathrm{n}^{\mathrm{o}}$ 106/2020] Disponível em: $<$ https://bityli.com/g3S8P $>$. Acesso em: 17 jun. 2020.

BRASIL. Ministério da Educação. BNCC na prática. Equipe educacional da Editora. São Paulo: FTD, 2018.

CAETANO. M. R.; PERONI, V. M. V. O público e o privado na educação. Projetos em disputa? Revista Retratos da Escola, Brasília, v. 9, n. 17, p. 337-352, jul./dez. 2015. Disponível em: <http://www.esforce.org.br/>. Acesso em: jan. 2019.

CERTEAU, M. de. A invenção do cotidiano: artes de fazer. Petrópolis: Vozes, 1998.

COPE, B.; KALANTZIS, M. (Orgs.). Multiliteracies: literacy learning and the design of social futures. New York: Routledge, 2006.

FERRAÇO, C. E.; SOARES, C.; ALVES, N. Michel de Certeau e as pesquisas nos/dos/com os cotidianos na Educação. Rio de Janeiro: EdUERJ, 2018.

FREIRE, P. Pedagogia do Oprimido. 59. ed. rev. atual. Rio de Janeiro: Paz e Terra, 2015.

FREIRE, P. Pedagogia da Indignação. São Paulo: Editora Unesp, 2000.

G1. Economia. Nova atualização do whatsapp permite fazer ligação de vídeo com até 8 pessoas. Globo, Rio de Janeiro, 28 de abril de 2020. Disponível em:

$<$ https://bityli.com/oXs4i>. Acesso em: 13 jun. 2020.

GARCIA CANCLINI, N. Diferentes, desiguais e desconectados: mapas da interculturalidade. 2. ed. Rio de Janeiro: Ed. UFRJ, 2009.

JUNQUEIRA, E. Atividade escolar remota não é EAD. O Povo, Fortaleza, 15 maio 2020. Disponível em: $<$ https://bityli.com/Qbc6C $>$. Acesso em: 17 jun. 2020.

LEMOS, A.; CUNHA, P. (Orgs.). Olhares sobre a cibercultura. Porto Alegre: Sulina, 2003.

MACEDO, R. S. Pesquisa contrastiva e estudos multicascos: da crítica à razão comparativa ao método contrastivo em ciências sociais e educação. Salvador: Ed. UFBA, 2018.

MACEDO, R. S. Atos de currículo: formação em ato? Para compreender, entretecer e problematizar currículo e formação. 2. Reimpr. Ilhéus: Editora da UESC, 2014.

MACHADO, J. L. A. Diretrizes curriculares para EJA e a BNCC. Planeta Educação, [São José dos Campos], 23 ago. 2018. Disponível em: $<$ https://bityli.com/CjZdA $>$.Acesso em 14 jan. 2019.

MORIN, E. A cabeça bem-feita: repensar a reforma, reformar o pensamento. Rio de Janeiro: Bertrand Brasil, 2014.

PASTURA, C.; MATTOS, P.; ARAUJO, A. Desempenho escolar e transtorno do déficit de atenção e hiperatividade. Rev. Psiquiatr. Clín., São Paulo, v. 32, n. 6, p. 324-329, dec. 2005. Disponível em: $<$ https://bityli.com/3dnkW>. Acesso em: 17 jun. 2020. 
PIMENTEL, M.; ARAÚJO, R. Há conversação na aula online. SBC Horizontes, 5 abr. 2020. Disponível em: $<$ https://bityli.com/Fb4NF>. Acesso em: 17 jun. 2020.

PIMENTEL, M.; CARVALHO, F. S. P. Princípios da Educação Online: para sua aula não ficar massiva nem maçante. SBC Horizontes, maio 2020. Disponível em: $<$ https://bityli.com/mOy8h $\geq$. Acesso em: 15 jun. 2020.

PORTO, C.; OLIVEIRA, K.; ALVES, A. (Orgs.). WhatsApp e educação: entre mensagens, imagens e sons. Salvador: Ed. UFBA, 2017.

PRETTO, N. de L. Reflexões: ativismo, redes sociais e educação. Salvador: Ed. UFBA, 2013.

RIO DE JANEIRO (Estado). Decreto $\mathrm{n}^{\circ}$ 46.980, de 19 de março de 2020. Atualiza as medidas de enfrentamento da propagação decorrente do novo Coronavírus (Covid-19) em decorrência da situação de emergência em saúde e dá outras providências. Diário Oficial do Estado, Rio de Janeiro, Poder Executivo, ano 46, n. 47, p. 24, 13 de Março de 2020. Disponível em: $<$ https://bityli.com/RBaQj $>$. Acesso em: 17 jun. 2020.

ROJO, R. (Org.). Escola conectada: os multiletramentos e as TICs. São Paulo: Parábola, 2013.

SANTAELLA, L. Comunicação ubíqua: repercussões na cultura e na educação. São Paulo: Paulus, 2013.

SANTAELLA, L. Culturas e artes do pós-humano: da cultura das mídias à cibercultura. São Paulo: Paulus, 2003.

SANTANA L.; AMARAL, M., Letramentos digitais potencializados por ambiências formativas híbridas Revista Educação em Foco, v. 25, n. 1, jan. / abr. 2020. Disponível em https://periodicos.ufjf.br/index.php/edufoco/article/view/30430. Acesso em 10 jun. 2020.

SANTOS, E. Educação online para além da EAD: um fenômeno da cibercultura. In: CONGRESSO INTERNACIONAL GALEGO-PORTUGUÊS DE PSICOPEDAGOGIA, 10., 2009, Braga. Actas. Braga: Universidade do Minho, 2009. p. 5.658-5.671. Disponível em: $<$ https://bityli.com/SzrAv> Acesso em: 17 jun. 2020

SANTOS, E. Pesquisa-formação na cibercultura. Teresina: Ed. UFPI, 2019.

SANTOS, E.;ARAÚJO,M. M. Como avaliar a aprendizagem online? Notas para inspirar o desenho didático online. Educação em Foco, Juiz de Fora, v. 17, n. 2, p. 103-119, jul./out. 2012.

SANTOS, E.; CAPUTO, S. (Orgs.). Diário de pesquisa na cibercultura: narrativas multirreferenciais com os cotidianos. Rio de Janeiro: Omodê, 2018.

SANTOS, E.; TRACTENBERG, L. Educação online e docência colaborativa, [10 jun. 2020]. 1 vídeo (1:53min) [Entrevista cedida a] Calorney Alves. Publicado no canal GPTPEM UFAL. Disponível em: https://bityli.com/sVSCr. Acesso em: 17 jun. 2020.

SILVA, M. (Org.). Educação online. São Paulo: Loyola, 2003.

SILVA, M.; SILVA, M. Educar na cibercultura. desafios a formação de professores para docência em cursos online. Revista Digital de Tecnologias Cognitivas, São Paulo, n. 3, jan./jun. 2010. Disponível em: <https://bityli.com/txXiX>. Acesso em: 5 ago. 2019. 
STREET, Brian. What's "new" in new literacy studies? Critical approaches to literacy in theory and practice. Current Issues in Comparative Education, Columbia, v. 5, n. 2, p. 77-91, 2003.

TARDIF, M. Saberes docentes e formação profissional. Petrópolis: Vozes, 2002.

XAVIER, A. C.Letramento digital e ensino. In: SANTOS, Carmi Ferraz; MENDONÇA, Márcia (Orgs.). Alfabetização e letramento: conceitos e relações. Belo Horizonte: Autêntica, 2005. p. 133-148.

\begin{abstract}
${ }^{i}$ Mestre em Educação pelo Programa de Pós-Graduação em Educação, Cultura e Comunicação (PPGECC) da Faculdade de Educação da Baixada Fluminense (FEBF/UERJ) Duque de Caxias/ Rio de Janeiro, Brasil. E-mail santana.s.leila@gmail.com. ORCID: https://orcid.org/0000-0003-0646-2938
\end{abstract}

ii Mestranda em Educação pelo Programa de Pós-Graduação em Educação, Cultura e Comunicação (PPGECC) da Faculdade de Educação da Baixada Fluminense (FEBF/UERJ) Duque de Caxias/ Rio de Janeiro, Brasil. Email luciaandrade.bib@gmail.com. ORCID: https://orcid.org/0000-0002-7709-3431

iii Professora Adjunta do Departamento de Ciências Sociais e Educação (UERJ) e do Programa de PósGraduação em Educação, Cultura e Comunicação (PPGECC) da Faculdade de Educação da Baixada Fluminense (FEBF/UERJ) Duque de Caxias/ Rio de Janeiro, Brasil. E-mail lucianavss@gmail.com.ORCID: https://orcid.org/0000-0002-6832-4189

\begin{abstract}
${ }^{\text {iv }}$ Mestranda em Educação pelo Programa de Pós-Graduação em Educação, Cultura e Comunicação (PPGECC) da Faculdade de Educação da Baixada Fluminense (FEBF/UERJ) Duque de Caxias/ Rio de Janeiro, Brasil. Email tamiresreis.pedagogiauerj@gmail.com. ORCID: https://orcid.org/0000-0002-2078-387X
\end{abstract}

v Fonte: https://www.vagalume.com.br/g-r-e-s-uniao-da-ilha-do-governador/samba-enredo-1978.html. Acesso em: 05 maio 2020.

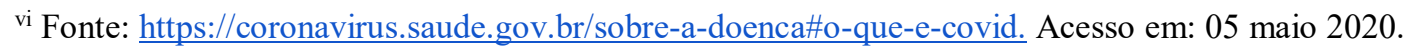

vii Fonte: https://nacoesunidas.org/tema/coronavirus/ Acesso em: 05 maio 2020.

viii Adotamos o uso dos termos 'docentesdiscentes', 'espaçostempos', 'conhecimentossignificações', 'ensinoaprendizagem' entre outros, assim grafados, por entender que "as dicotomias necessárias à criação das ciências na Modernidade têm significado limites ao que precisamos criar na corrente de pesquisa a que pertencemos. Com isso, passamos a grafar desse modo os termos de dicotomias herdadas: juntos, em itálico e entre aspas simples. Estas últimas foram acrescentadas com vistas a deixar claro aos revisores/as de textos que é assim que esses termos precisam aparecer" (ANDRADE; CALDAS; ALVES, 2019, p. 19).

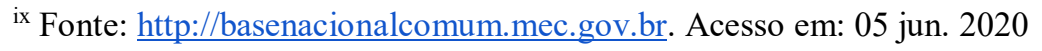

x Para ler a letra completa, acesse: https://www.vagalume.com.br/gonzaguinha/nunca-pare-de-sonhar.html

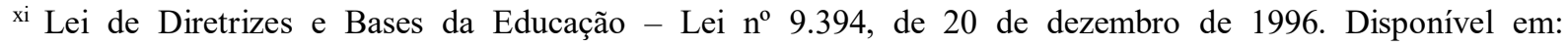
https://www.planalto.gov.br/ccivil 03/Leis/L9394.htm. Acesso em: 05 maio 2020.

xii Live Educação a Distância: Universidade e Pandemia. Disponível em:

https://www.youtube.com/watch?v=PWmuNdt7dAc. Acesso em: jun. 2020.

xiii Concordamos com Macedo (2010) ao pensarmos que os atos de currículos fazem parte da práxis formativa; dessa forma, trazem sentido de não encerrar a formação num fenômeno externo determinado pela mecânica curricular (p. 35).

${ }^{\text {xiv }}$ Para ter a letra completa, acesse: https://www.letras.mus.br/raul-seixas/48317/. Acesso em: 17 jun. 2020.

Revista Interinstitucional Artes de Educar. Rio de Janeiro, V. 6 - N. Especial - pág. 301 - 324 - (jun. - out. 2020): 
${ }^{x v}$ O Google Classroom é um aplicativo para gerenciamento de conteúdos para usuários que possuam uma conta pessoal no Google. É gratuito para escolas, organizações sem fins lucrativos. Google Classroom. Disponível em: https://classroom.google.com/u/0/h. Acesso em: 13 jun. 2020.

xvi Disponível em: https://pge.rj.gov.br/comum/code/MostrarArquivo.php?C=MTAyMTk\%2C. Acesso em: 17 jun. 2020.

xvii Disponível em: https://meet.google.com/. Acesso em 17 jun. 2020.

xviii As palavras alunofilho foram grafadas juntas e em itálico porque nesse momento essas identidades se relacionavam diretamente ao longo do aprendizado da metodologia educacional proposta pela escola.

${ }^{\text {xix }} \mathrm{A}$ frase não faz sentido, pois mostra a confusão da pesquisadora em desempenhar tantos papeis e ensinar matérias em diferentes campos. A constante de Avogadro é um valor numérico utilizado em Química. O aluno do Ensino Médio na escola onde estuda, fonte da observação de uma das pesquisadoras, está iniciando os estudos nesta matéria pelo ensino não presencial.

${ }^{x x}$ Sobre TDAH (transtorno de déficit de atenção e aprendizagem), consultar PASTURA, C.; MATTOS, P.; ARAUJO (2005).

xxi Plataforma que permite aos usuários compartilhar, fazer perguntas e responder questões de matérias escolares. Disponível em: https://brainly.com.br/. Acesso em: 17 jun. 2020.

xxii Para a letra completa acesse: https://www.vagalume.com.br/natiruts/tudo-vai-dar-certo.html. Acesso em: 05 maio 2020 .

xxiii Disponível em: http://www.planalto.gov.br/CCIVIL_03/Ato2011-2014/2014/Lei/L12965.htm. Acesso em: jun. 2020.

xxiv Termo usado por Marie-Christine Josso (2004), ampliado por Edméa Santos (2014), indicando um contexto de pesquisa em que 'docentesdiscentes' se formam e formam a partir das experiências vivenciadas no contexto da cibercultura.

xxv Disponível em: https://artsandculture.google.com/partner/museu-do-amanh\%C3\%A3. Acesso em: jun. 2020.

${ }^{x x v i}$ Fonte: https://www.letras.mus.br/renato-russo/1213616/. Acessado em 05 jun. 2020

xxvii Disponível em: https://www.vagalume.com.br/elis-regina/aprendendo-a-jogar.html. Acesso em: jun. 2020.

Revista Interinstitucional Artes de Educar. Rio de Janeiro, V. 6 - N. Especial - pág. 301 - 324 - (jun. - out. 2020): 